\title{
The Emerging Role of Anterior Segment Optical Coherence Tomography in Cataract Surgery: Current Role and Future Perspectives
}

This article was published in the following Dove Press journal: Clinical Ophthalmology

\section{Amar Pujari 1 \\ Namrata Sharma (iD) \\ Dr. Rajendra Prasad Centre for Ophthalmic Sciences, All India Institute of Medical Sciences (AllMS), New Delhi, India}

\begin{abstract}
Modern-day cataract surgery has achieved equivalence with refractive surgery, thus requiring surgeons to perform all possible pre-emptive exercises to mitigate intraoperative complications. In this direction, we possess a tremendous amount of technology to understand the preoperative status of the lens. Anterior segment optical coherence tomography (ASOCT) is one such tool, which has played a distinctive role in imaging various forms of cataracts. In this review, we critically analyse the practical role of ASOCT in the preoperative and intraoperative periods from a cataract surgeon's perspective. After a thorough literature assessment, it was substantiated that the cross-sectional imaging ability of ASOCT can demonstrate delicate anatomical and pathological lenticular changes in a visually and clinically comprehensible way. The objective grading of immature cataracts to intralenticular and posterior capsular details in mature/white, posterior polar, traumatic and other forms of cataracts paves the way for various practical innovations as and when required. Hence, preoperative more than intraoperative ASOCT-derived lenticular knowledge is of immense help in careful surgical planning, with improved complication rates.
\end{abstract}

Keywords: anterior segment optical coherence tomography and cataract, cataract, anterior segment optical coherence tomography

\section{Introduction}

Optical coherence tomography (OCT) now has an indispensable role in ophthalmology, with evaluation of ocular biometry, morphological and crosssectional changes now being possible in very little time. Ultrasonography (USG) and ultrasound biomicroscopy (UBM) are other tools that have proven their definitive role in ocular imaging; however, owing to its non-contact and non-invasive abilities, and with constant evolutions in the technology, OCT remains the most popular tool. Apart from these preoperative and postoperative roles, intraoperative real-time assessment of various surgical events is also possible with OCT.

Anterior segment optical coherence tomography (ASOCT) provides crosssectional details of ocular tissues from the corneal surface to the anterior hyaloid face (Figure 1, Video 1). ${ }^{1}$ Using this sophisticated technology, we are able to image the tissue details in micrometres with good clinical reproducibility. ${ }^{1}$ The advantages of ASOCT in measuring corneal and anterior chamber angles have often been
Correspondence: Amar Pujari Ophthalmic Sciences, All India Institute of Medical Sciences (AIIMS), Room No. 212,

RPC-I, New Delhi, India

Tel +918447226221

Email dramarpujari@gmail.com 


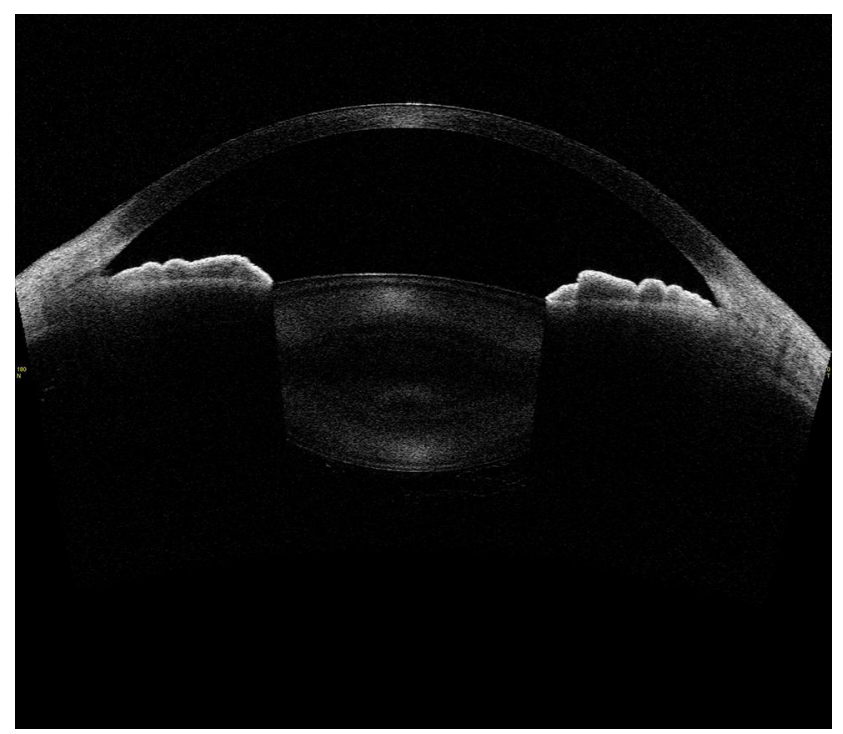

Figure I The normal extent of the anterior segment captured with SS-OCT technology in one frame.

highlighted in the literature; however, the use of ASOCT in cataract surgery is new, and hence understanding its critical role in the management of lens-related diseases is of paramount importance. To our knowledge, there have been no dedicated reviews compiling the ASOCT-derived information for cataract surgeons. Therefore, based on our previous work on various aspects of ASOCT, we discuss the point-focused utility of ASOCT in cataract surgery and for cataract surgeons. The unique clinical details of ASOCT, in both the preoperative and intraoperative periods, are described and discussed.

\section{Methods}

A thorough literature search was conducted on PubMed Medline, Scopus and Web of Science using the following keywords: anterior segment optical coherence tomography and cataract, cataract, and anterior segment optical coherence tomography. Studies, observations and reports highlighting the beneficial role of ASOCT in cataract surgery and for cataract surgeons were included in the assessment. Studies describing the biometric role of ASOCT and other theoretical concepts were excluded. These selection criteria were followed because ASOCT observations with direct or indirect impacts on the surgeon may influence the surgical planning by a particular surgeon. The full text of all included articles was accessed and in-depth analysis was performed to gather constructive knowledge.
Finally, appropriate real-time conclusions were drawn, with limitations and suggestions for future directions to improve on the same.

\section{Observations}

After reviewing the literature, situations in which ASOCT can assist in lenticular pathologies were divided into six subsections with respect to their clinical relevance.

\section{Early Cataracts}

The development of cataract and its progression are associated with the formation of denser nuclei. To stage such changes, the existing lens opacity classification system (LOCS) is able to grade the severity of cataracts so as to guide the surgeon in customizing intraoperative phacoemulsification parameters. However, owing to the observer's experience and possible bias, variability in grading cannot be ignored. To address these limitations, researchers have continuously explored the possibility of an automated grading system on ASOCT. In different observations, the LOCS-derived nuclear opalescence and nuclear colours were correlated with ASOCT-derived nuclear density values. In 2009, Wong et al described the comparative results of LOCS III system and ASOCT-derived nuclear density parameters. ${ }^{2}$ They noted a significant correlation between the two. This work has progressed considerably since then. ${ }^{3-5}$ Panthier et al discussed the reliability of nuclear density in considering cataract surgery in 2017, and in 2019, they presented an updated algorithm of average lens density for possible surgical communication with patients considered for cataract surgery. The average lens density of 73.8 pixel units was suggestive of cataract, with more than $95 \%$ sensitivity and more than $90 \%$ specificity. $^{6,7}$ Hence, in cases of immature cataracts, in addition to the visual acuity of the patient, automated nuclear density data may guide the surgical options in future. As the visual acuity may not always reflect the severity of cataract, an automated, universally tested and acceptable objective grading system can provide a common ground for surgical decisions. In addition, such grading remarks could be used to guide the customization of intraoperative energy parameters.

Similarly, the other noted utility of ASOCT, in combination with a femtosecond laser, is that it can 
provide greater anatomical detail of the tissues, which was previously often thought to be difficult. The realtime in vivo changes along the lens, ${ }^{8,9}$ laser dissection depths and paths, ${ }^{10}$ laser parameter variations with lens thickness and density, ${ }^{11}$ identification of Berger space, laser capsulotomy details ${ }^{12,13}$ and others have been observed more pragmatically until now. ${ }^{14}$ Thus, these constructive observations broaden the scope of ASOCT in lenticular diseases.

\section{Posterior Subcapsular Cataracts}

Enaida et al observed transient posterior subcapsular cataract formation on swept source ASOCT (SS-ASOCT). The clinical appearance of vacuolar changes along the posterior subcapsular region was very closely correlated with the ASOCT findings. Similarly, as the opacity regressed clinically, ASOCT also projected its graded disappearance. $^{15}$

\section{Mature/Hypermature/White Cataracts}

White cataracts, including mature and hypermature cataracts, have the potential to influence the intraoperative course dramatically if the necessary precautions are not exercised. Because of denser cataracts, intralenticular and posterior capsular changes are often elusive in the preoperative period. Dhami et al segregated the mature white cataracts on ASOCT into two groups, with and without subcapsular fluid; they noted that the ASOCT-guided observations helped in reducing the intrabag pressures at appropriate times by performing targeted needle aspirations. $^{16}$

Similarly, Titiyal et al also observed white cataracts, but they used intraoperative microscope integrated OCT (iOCT). The authors were able to successfully categorize these cases into four subtypes, based on the amount of disorganized lens fibres and the accumulated liquefied material. Therefore, similar to the previous observations, the iOCT was also very quick in demonstrating the extent of fluid collection, and in prompting a rescue strategy to minimize the capsular runaway complications. ${ }^{17}$

However, these studies have hardly stated the possible natural progression of intralenticular changes, because not all of these white and/or mature cataracts may possess significantly disorganized lens fibres and liquefied material at the time of surgery. Hence, to fill these gaps in our understanding, we worked on mature cataracts to organize the possible intralenticular changes in the preoperative period on a modified posterior segment OCT. (We modified the posterior segment OCT to an anterior segment OCT by placing a $+20 \mathrm{D}$ lens along its aperture.) In that observation, 44 eyes with mature cataract were cross-sectionally assessed to understand the course of lamellar separation, progression, and the accumulation of liquefied material, with visible changes along the anterior lens curvature. Stage I was characterized as "vacuolation" or "early lamellar separation", where tiny hypoechoic areas within the anterior lens substance suggested the possible early phases of horizontal lens fibre separation; however, this being an early physiological event, extensive lens matter liquefaction (echo-free, completely dark areas) and a more convex anterior lens curvature were not seen. Hence, these cases carried no risk of rhexis-related intraoperative complications (Figure 2). In stage II, owing to advanced lens fibre liquefaction/lysis, an "established stage of lamellar separation" with wider hypoechoic areas was seen; again, here, the anterior lens showed minimal bulge and possessed no frank liquefied lens matter; hence, again, eyes in this stage posed fewer rhexis-related

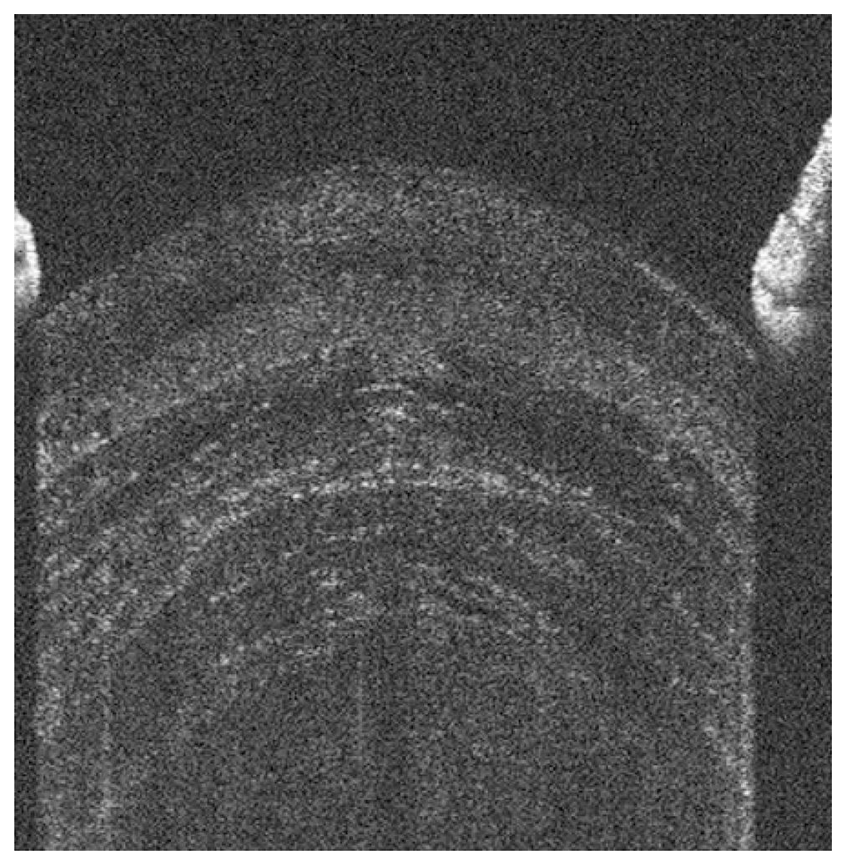

Figure 2 In a mature senile cataract, lenticular imaging on a modified OCT shows the presence of horizontal hypoechoic areas within the anterior cortex. It can also be noted that there is no collection of liquefied material in the lens and the anterior lens curvature is normal. This is the stage of early lamellar separation.

Note: Reproduced from Pujari A, Selvan H, Urkude J, Singh R, Mukhija R, Yadav S, Makwana T, Sharma N. Intralenticular changes in eyes with mature senile cataract on modified posterior segment optical coherence tomography. Indian J Ophthalmol. 2020;68:2099-2102. 


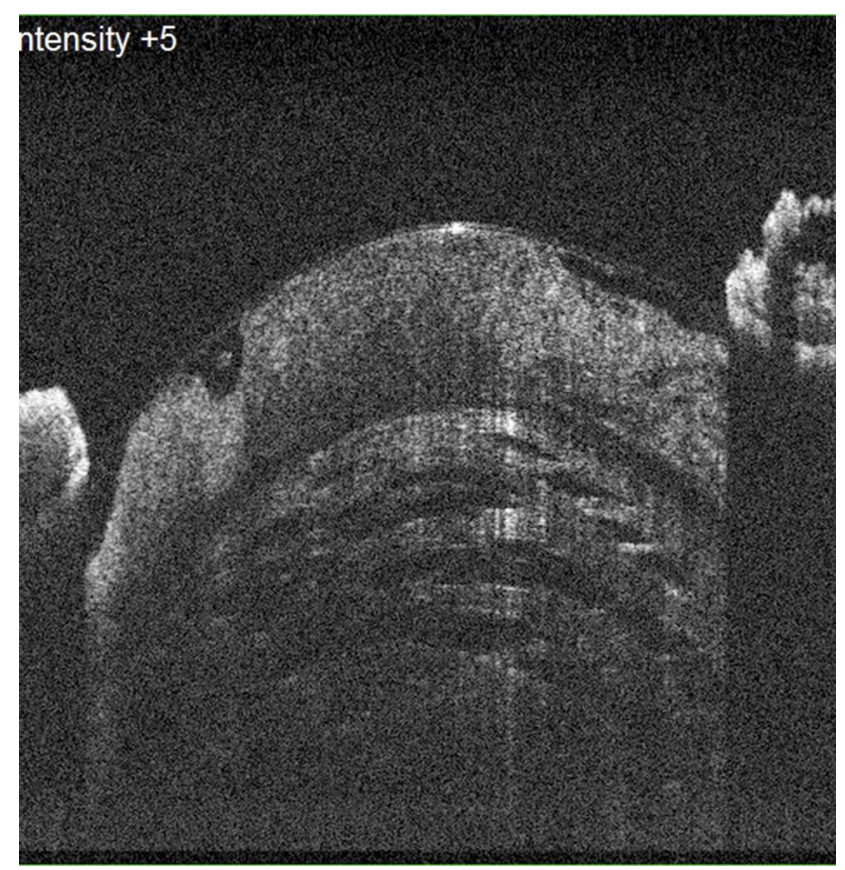

Figure 3 In the next stage of mature cataract, the separation becomes more advanced with little collection of liquefied material and minimal anterior lens bulging. This is the stage of established lamellar separation.

Note: Reproduced from Pujari A, Selvan H, Urkude J, Singh R, Mukhija R, Yadav S, Makwana T, Sharma N. Intralenticular changes in eyes with mature senile cataract on modified posterior segment optical coherence tomography. Indian J Ophthalmol. 2020;68:2099-2102. ${ }^{18}$

challenges (Figure 3). In the more advanced stage III circumstances, the lens showed extensive lysis of its framework with exaggerated accumulation of liquefied material. In this stage, the anterior lens also showed a pronounced anterior bulge, and hence, these eyes carried the maximum risk of rhexis-related complications (Figure 4). ${ }^{18}$ Similar to this, we also observed intralenticular changes in three mature brown cataracts, but the changes were variable along the anterior cortex and the anterior nucleus owing to the limited number of cases. ${ }^{19} 18$

De Castro et al studied cataractous eyes on an SS-OCT prototype, and they demarcated both hyporeflective and hyperreflective areas along the lenticular cortex. The hyperreflective areas represented cortical cataracts, whereas the hyporeflective areas represented the hollowed lens substances along the anterior as well as the posterior cortex. ${ }^{20}$ According to cumulative evidence in the literature, these hyporeflective areas can be considered as early liquefactive changes, and, therefore, such observations emphasize the definitive role of preoperative as well as intraoperative OCT in the better understanding of physiological events of advanced cataracts (Figure 5 and Table 1).

\section{Traumatic Cataracts}

The utilization of ASOCT in assessing traumatic lens injuries is limited. The majority of articles were isolated observations or case reports, which highlighted the anterior cortical, posterior capsular, phacocele and retained intralenticular foreign bodies. Traumatic cases are often challenging with grossly disturbed lenticular and perilenticular anatomical orientations; hence, ASOCT paves the way for surgeons to formulate a customized treatment strategy in each case. ${ }^{21-23}$ In a large case series, Tabatabaei et al compared SS-ASOCT with UBM to

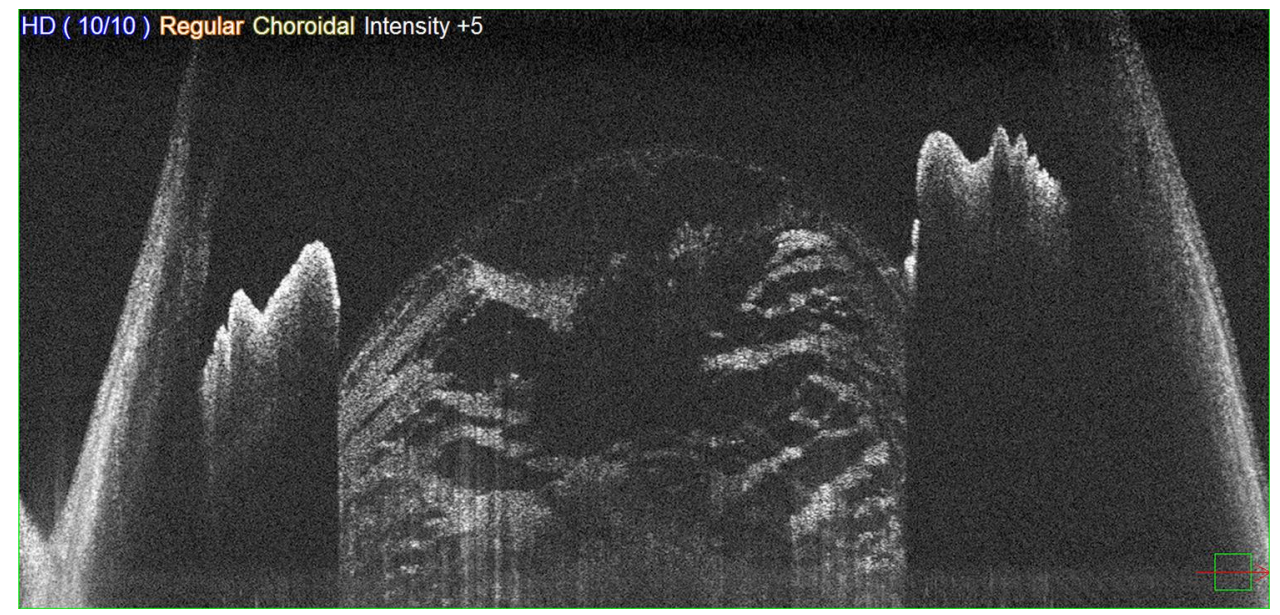

Figure 4 In the most advanced stage, a major portion of the anterior lens framework is lysed; hence, with subsequent collection of liquefied material, the anterior capsule bulges forward. This stage indicates extensive collection of liquefied material and raised intrabag pressures, which harbour the risk of capsule-related complications. This is the stage of liquefaction. 


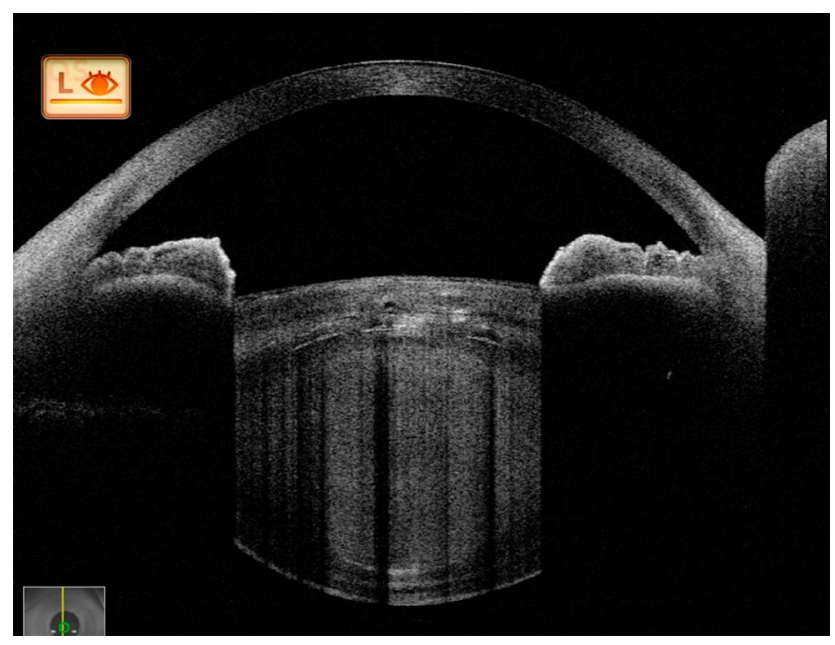

Figure $\mathbf{5}$ In a moderately dense cataract, posterior cortical and capsular details are better appreciated on cross-sectional imaging.

determine the predictability of posterior capsule rupture in traumatic cataracts. They discovered that ASOCT was superior to UBM in terms of its sensitivity, specificity, and positive and negative predictive values. ${ }^{24}$ In our previous observation, which involved three post-traumatic cataracts, posterior capsular rupture was very clearly defined in all eyes on a modified OCT. Therefore, with newer SS-OCT or simple modifications, traumatic cataracts could be better imaged as well as better managed (Figures 6-9 and Table 2) (Video 2, 3 ).

\section{Posterior Polar Cataracts}

Posterior polar cataracts (PPCs) are also clinically challenging. The small discoid opacity at the posterior pole usually hinders the underlying capsular integrity during clinical assessment, and, therefore, higher intraoperative rents are inevitable. Hence, to mitigate such complications, cross-sectional imaging of the lens is mandatory.

Since 2014, various authors have described different ASOCT-based observations; in all of these studies attempts have been made to segregate the dehiscent capsule from the intact one. Initially, Kymionis et al

Table I ASOCT-Noted Observations Among Mature/Hypermature/White Cataracts

\begin{tabular}{|c|c|c|c|c|c|}
\hline Authors (year) & $\begin{array}{l}\text { Objective of } \\
\text { the Study }\end{array}$ & $\begin{array}{l}\text { Number } \\
\text { of Eyes }\end{array}$ & ASOCT Type & Observations & Learning Points \\
\hline $\begin{array}{l}\text { Dhami et al } \\
(2019)^{16}\end{array}$ & $\begin{array}{l}\text { To study the role } \\
\text { of ASOCT in } \\
\text { imaging mature } \\
\text { white cataracts }\end{array}$ & 30 eyes & $\begin{array}{l}\text { Spectral domain OCT } \\
\text { (Cirrus HD-OCT, Carl } \\
\text { Zeiss Meditec) }\end{array}$ & $\begin{array}{l}\text { ASOCT helped in segregating } \\
\text { mature white cataractous eyes } \\
\text { into with (50\%) or without (50\%) } \\
\text { subcapsular fluid pockets }\end{array}$ & $\begin{array}{l}\text { The delineation of fluid } \\
\text { pockets underneath may } \\
\text { help in decreasing the } \\
\text { capsular runaway related } \\
\text { complications }\end{array}$ \\
\hline $\begin{array}{l}\text { Pujari et al } \\
\text { (2019); our } \\
\text { study } 19\end{array}$ & $\begin{array}{l}\text { To note the } \\
\text { intralenticular } \\
\text { changes in } \\
\text { mature brown } \\
\text { cataracts }\end{array}$ & 3 eyes & $\begin{array}{l}\text { RS-3000, OCT Retina scan } \\
\text { Advance (Nidek) with } \\
\text { a }+20 \text { D dioptre lens at its } \\
\text { aperture, and } \\
\text { intraoperative OCT } \\
\text { (iOCT) }\end{array}$ & $\begin{array}{l}\text { The mature brown cataracts } \\
\text { showed varying grades of } \\
\text { anterior cortical and possibly } \\
\text { nuclear lamellar separation with } \\
\text { liquefaction of lens matter }\end{array}$ & $\begin{array}{l}\text { ASOCT can show } \\
\text { possible lamellar and } \\
\text { liquefactive changes in } \\
\text { mature brown cataracts }\end{array}$ \\
\hline $\begin{array}{l}\text { Titiyal et al } \\
(2020)^{17}\end{array}$ & $\begin{array}{l}\text { To assess the } \\
\text { morphological } \\
\text { and different } \\
\text { dynamics of } \\
\text { white cataracts } \\
\text { on iOCT }\end{array}$ & 50 eyes & $\begin{array}{l}\text { iOCT (OPMI Lumera } 700 \\
\text { and RESCAN 700) }\end{array}$ & $\begin{array}{l}\text { The white cataracts were } \\
\text { identified as four types }\end{array}$ & $\begin{array}{l}\text { The iOCT can help in } \\
\text { elucidating intraoperative } \\
\text { dynamics of mature } \\
\text { cataracts with facilitation } \\
\text { to uncomplicated } \\
\text { capsulorhexis }\end{array}$ \\
\hline $\begin{array}{l}\text { Pujari et al } \\
(2020) \text {; our } \\
\text { study }^{18}\end{array}$ & $\begin{array}{l}\text { To study the } \\
\text { morphological } \\
\text { changes in } \\
\text { mature senile } \\
\text { cataracts }\end{array}$ & 44 eyes & $\begin{array}{l}\text { RS-3000, OCT Retina scan } \\
\text { Advance (Nidek) with } \\
\text { a }+20 \text { D dioptre lens at its } \\
\text { aperture }\end{array}$ & $\begin{array}{l}\text { Mature senile cataracts were } \\
\text { classified into three stages: I) } \\
\text { early lamellar separation/ } \\
\text { vacuolation, 2) established } \\
\text { lamellar separation, and 3) stage } \\
\text { of liquefaction }\end{array}$ & $\begin{array}{l}\text { Modified AS-OCT can } \\
\text { help in understanding the } \\
\text { natural sequential } \\
\text { changes in MSC eyes }\end{array}$ \\
\hline
\end{tabular}




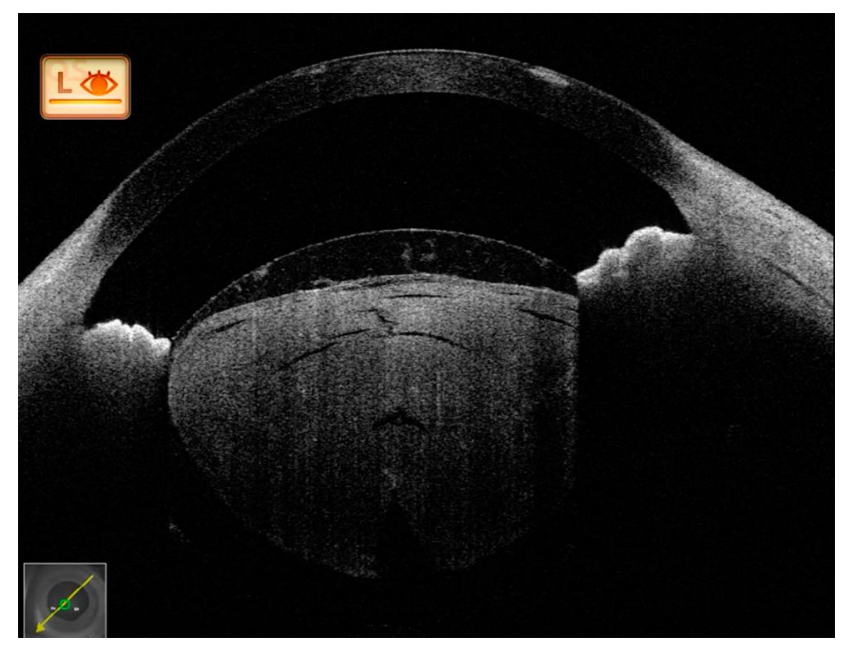

Figure 6 In a traumatic cataract with globular lens, its morphology, intralenticular changes, anterior subcapsular collection and a possible posterior defect are noted. The posterior defect needs to be further assessed on ImageJ software or MATLAB software with increased brightness and reduced background noise so as to clarify further its intactness.

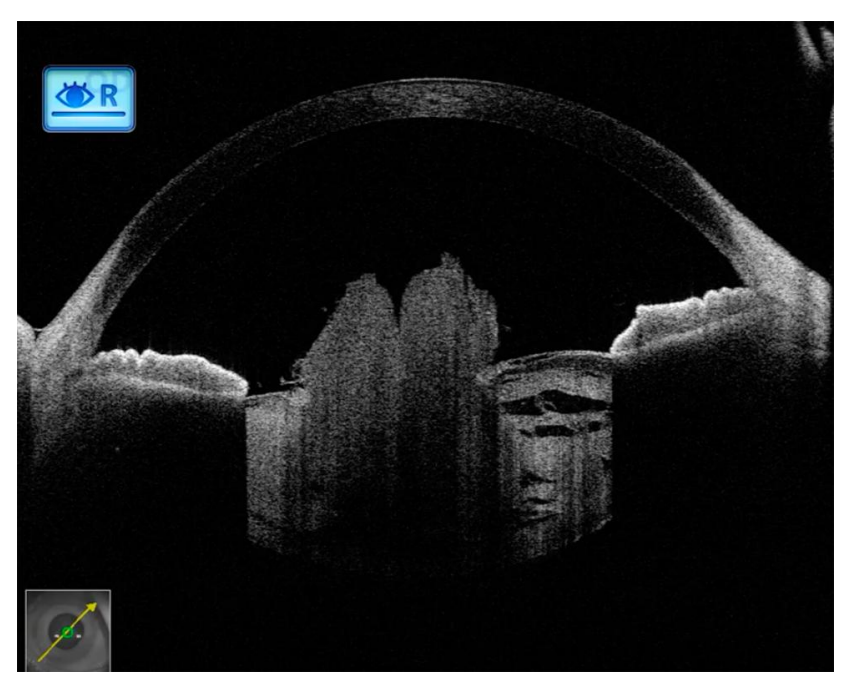

Figure 7 Post-traumatic cataract with partially absorbed lens matter showing a ruptured anterior capsule and matter spilling over into the anterior chamber. Again, here, in the presence of anterior dense opacity, posterior capsular details are very well appreciated before surgery.

stated that the posterior capsular integrity was dehiscent in two cases and intact in a third. ${ }^{25}$ In the same year, Chan et al and subsequently in 2018 Kumar et al described similar features. ${ }^{26,27}$ However, owing to the limited number of cases and to the low resolution of the scans, it is possible that some cases may have been overdiagnosed as dehiscent capsules. Further, to elicit a dehiscent capsule intraoperatively,
Sachdev et al used femtosecond laser integrated OCT, and they stated that the capsule was either intact or dehiscent by tracing it beneath the opacity. If it was not traced beneath the posterior pole opacity then it was labelled as dehiscent; in this manner, they predicted $14 \%$ of the cases to be dehiscent, but only $10 \%$ of them had intraoperative dehiscence ${ }^{28}$

From these cumulative observations, the clear discrepancy between the ASOCT predictions and the actual intraoperative findings points at other possible hidden features. Our initial experiences from a limited number of cases (26 eyes) on the modified posterior segment OCT with a $+20 \mathrm{D}$ lens revealed that the posterior capsule was definitely lacking or had a "definite dearth" in four eyes (15.38\%) (Figure 10). ${ }^{29}$ Considering previous limitations, to overcome both the magnification- and clarity-related issues, in our studies we state two equally important factors, namely the "capsule" and the "contour", when making the final comments. First, the "capsule" should to be traced from an adjacent paracentral region to the posterior most dependent portion from either side, and if it is clearly made out in its entirety, then it can be labelled as an intact capsule; however, if the scan quality or undermagnification hinders any of these judgements, then the concerns over the scan quality and magnification must be addressed on the machine itself or using photo editing software, before reaching any conclusions. Secondly, the regular posterior convex "contour" of the lens, of which we are all aware and which we have regularly witnessed, should be the next criteria. If it follows a regular contour, then it can be labelled as normal; however, any magnification- and scan quality-related issues must be addressed first, as stated above. This contour can deviate in three possible directions: the "conical sign", where an active herniation of the lens matter into the anterior vitreous cavity can present with such appearance (Figure 11); similarly, in the "moth-eaten" appearance (Figure 12), the lens excavation takes an opposite path, that is, into the posterior lens substance; and in the third appearance the contour shows a zig-zag ("ectatic") appearance, possibly suggesting an inherently weaker posterior capsule. Using all of these criteria in our second observation on SS-ASOCT in 101 eyes, we systematically categorized posterior polar cataracts as specific 

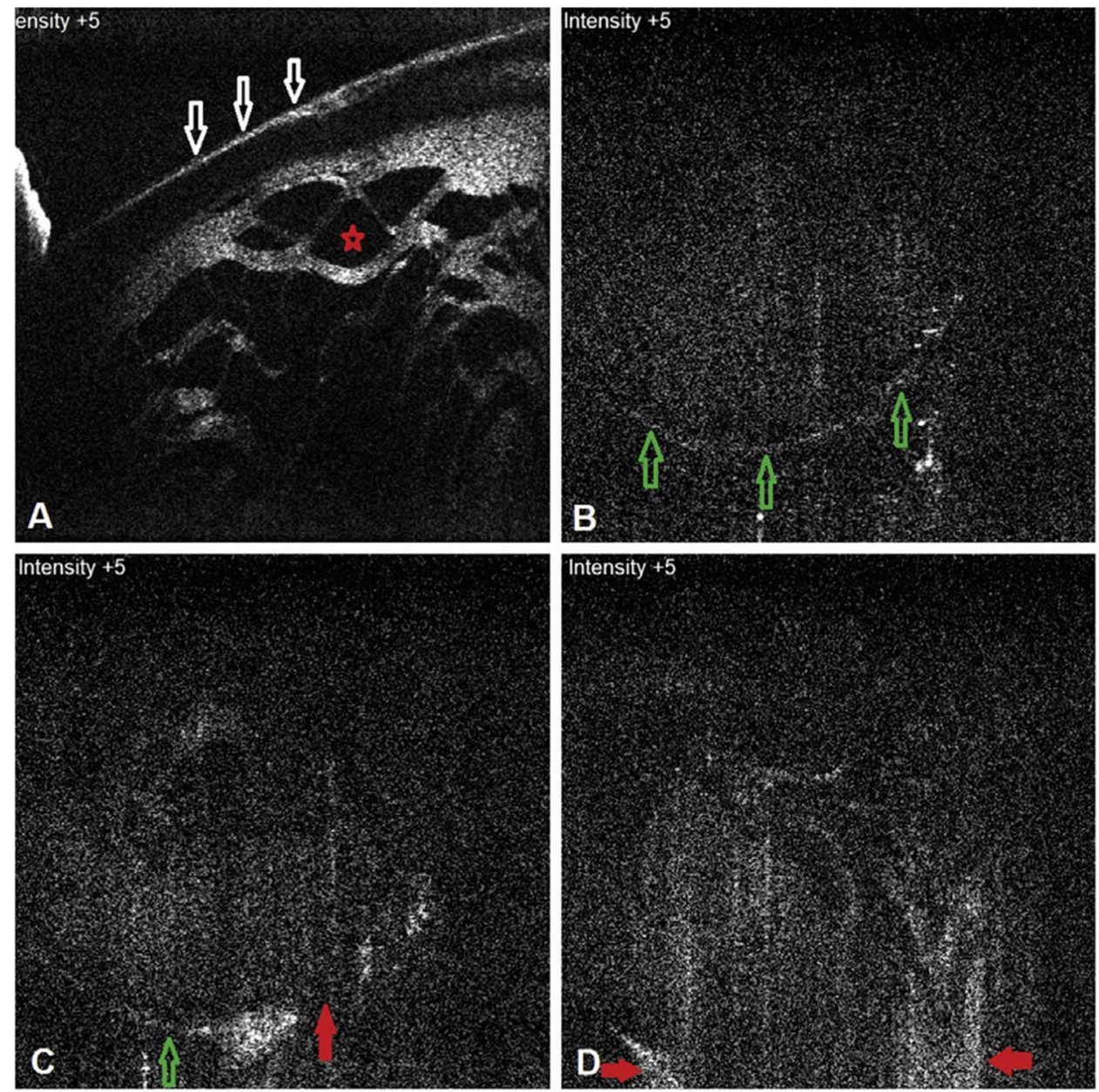

Figure 8 In a traumatic case, in its anterior portion, the anterior capsular flattening (white arrows) and cortical matter desiccation (red star) (A) can be appreciated. In further deeper scans, continuously appreciable intact posterior capsule (green arrows) (B), and an intact (green arrow) as well as discontinuous (red arrow) posterior capsule can be appreciated (C and $\mathbf{D})$, with active herniation of cortical matter.

Note: Reproduced from Pujari A, Sharma N. Post traumatic posterior capsular defect: assessment of 3 cases. J Cataract Refract Surg. 2019;45:I349-1350. ${ }^{37}$

morphologies and generalized morphologies (Figures 13, 14) (Video 4, 5). ${ }^{1}$ Hence, the newer SSASOCTs are able to provide better images from anterior cornea to the posterior capsule in a single frame. In addition, these images can be magnified up to 200 times, with enhanced finer details up to micrometres, and with minimally degraded image quality. ${ }^{1}$

To summarize, the ASOCT-related considerations in PPCs to decipher the posterior capsule as intact or dehiscent are growing. In this direction, the more deeply penetrating ASOCTs (such as SS-ASOCT) are able to provide better information. In future, when assessing the capsular status, this must be addressed from the "capsule" and "contour" perspectives in the presence of better quality and magnified scans (Table 3 ).

\section{Others}

In this subsection, the infrequent uses of ASOCT are summarized. In a report by Choudhry et al, an abandoned intraoperative cataract surgery eye was evaluated, even though it delineated intralenticular changes, but under these circumstances delineation of the posterior capsule and the anterior vitreous changes should be of utmost priority. ${ }^{30}$ Similarly, Asgari et al evaluated the effect of swirling lens fragments on endothelial cell counts using continuous intraoperative OCT. They were able to illustrate the crucial size of fragments and their common locations of endothelial contact. $^{31}$ Chen et al explored the innovative concept of robotic cataract surgery; their experiment involved a semi-automated procedure with constant feedback 
Table 2 Studies Highlighting the Role of ASOCT in Traumatic Cataracts

\begin{tabular}{|c|c|c|c|c|c|}
\hline Authors (year) & Objective of the Study & $\begin{array}{l}\text { Number } \\
\text { of Eyes }\end{array}$ & ASOCT Type & Observations & Learning Points \\
\hline $\begin{array}{l}\text { Prakash et al } \\
(2009)^{23}\end{array}$ & $\begin{array}{l}\text { To highlight the role of } \\
\text { ASOCT in non-contact } \\
\text { evaluation of traumatic } \\
\text { phacocele }\end{array}$ & I eye & Carl Zeiss Meditec & $\begin{array}{l}\text { ASOCT was helpful in } \\
\text { localizing the dislocated } \\
\text { lens into the } \\
\text { subconjunctival space }\end{array}$ & $\begin{array}{l}\text { ASOCT can be useful in non- } \\
\text { contact evaluation of hidden } \\
\text { lenticular changes }\end{array}$ \\
\hline $\begin{array}{l}\text { Mahendradas } \\
\text { et al }(2010)^{22}\end{array}$ & $\begin{array}{l}\text { To highlight the role of } \\
\text { ASOCT in localizing } \\
\text { retained intralenticular } \\
\text { foreign body }\end{array}$ & I eye & $\begin{array}{l}\text { Visante (Carl Zeiss } \\
\text { Meditec, Germany) }\end{array}$ & $\begin{array}{l}\text { ASOCT was helpful in } \\
\text { localizing the retained } \\
\text { intralenticular foreign } \\
\text { body }\end{array}$ & $\begin{array}{l}\text { ASOCT can localize deeply } \\
\text { situated intralenticular foreign } \\
\text { bodies in the presence of } \\
\text { cataract }\end{array}$ \\
\hline $\begin{array}{l}\text { Kuriyan et al } \\
(2012)^{21}\end{array}$ & $\begin{array}{l}\text { To highlight the role of } \\
\text { ASOCT in understanding } \\
\text { traumatic cataractous } \\
\text { changes }\end{array}$ & I eye & $\begin{array}{l}\text { Visante, model } 1000 \\
\text { (Carl Zeiss Meditec, } \\
\text { Dublin, CA }\end{array}$ & $\begin{array}{l}\text { ASOCT showed the } \\
\text { subcapsular vacuolating } \\
\text { changes in traumatic } \\
\text { cataract }\end{array}$ & - \\
\hline $\begin{array}{l}\text { Pujari et al } \\
(2019) \text {; our } \\
\text { observations }^{37}\end{array}$ & $\begin{array}{l}\text { To highlight the role of } \\
\text { modified posterior } \\
\text { segment OCT in imaging } \\
\text { traumatic lenses }\end{array}$ & 3 eyes & $\begin{array}{l}\text { RS-3000, OCT } \\
\text { Retina scan Advance } \\
\text { (Nidek) with a }+20 \\
\text { D dioptre lens at its } \\
\text { aperture }\end{array}$ & $\begin{array}{l}\text { The modified OCT } \\
\text { helped in localizing the } \\
\text { torn posterior capsule in } \\
\text { three traumatic } \\
\text { cataractous eyes }\end{array}$ & $\begin{array}{l}\text { Simple modification to } \\
\text { posterior segment OCT can } \\
\text { help by localizing the torn } \\
\text { posterior capsule in traumatic } \\
\text { cataracts }\end{array}$ \\
\hline $\begin{array}{l}\text { Tabatabaei et al } \\
(2020)^{24}\end{array}$ & $\begin{array}{l}\text { To assess the role of SS- } \\
\text { OCT and UBM in } \\
\text { detecting defective } \\
\text { posterior capsule in } \\
\text { traumatic cataracts }\end{array}$ & 67 eyes & $\begin{array}{l}\text { CASIA SS-1000, } \\
\text { Tomey (Nagoya, } \\
\text { Japan) }\end{array}$ & $\begin{array}{l}\text { The SS-OCT was } \\
\text { superior in special } \\
\text { circumstances in } \\
\text { delineating posttraumatic } \\
\text { PC rupture }\end{array}$ & $\begin{array}{l}\text { SS-OCT was recommended } \\
\text { for post-traumatic } \\
\text { cataractous eye evaluation }\end{array}$ \\
\hline
\end{tabular}

from intraoperative OCT. The OCT was helpful in anatomical modelling of anterior segment structures with clues for surgical paths and their alignment. Overall, it was able to provide real-time information to assist in carrying out successful surgery. ${ }^{32}$

\section{Discussion}

In clinical practice, opacification of the lens is a common end-stage feature of a variety of underlying causes and courses; hence, to delineate the covert changes, cross-sectional imaging of the lens has gained immense importance in recent times. In cataractous eyes, imaging can be performed either preoperatively or intraoperatively, and information gathered in this way has the ability to change the surgical planning, clinical course and, most importantly, the visual outcomes of an individual. Therefore, from the literature assessment it is clear that AS-OCT has provided valuable structural details from the anterior capsule to the posterior capsule, which were often hidden on slitlamp and/or routine clinical examinations. Information derived from the earlier OCTs was limited to either the anterior or posterior half of the lens; however, with continuing evolution in technology, detailed imaging of the entire lens is now possible in one frame. In addition, the featured three-dimensional reconstruction can drastically change the way in which we look at future ASOCT in cataract surgery. ${ }^{33}$

Similarly, the upcoming concept of whole eye imaging and ever-increasing use of intraoperative OCT in all forms of ocular surgeries can also revolutionize the way in which we think of the anterior and posterior segments together. ${ }^{34,35}$ However, before this tool becomes widely available to all clinicians, we recommend using the existing posterior segment OCT (RS- 

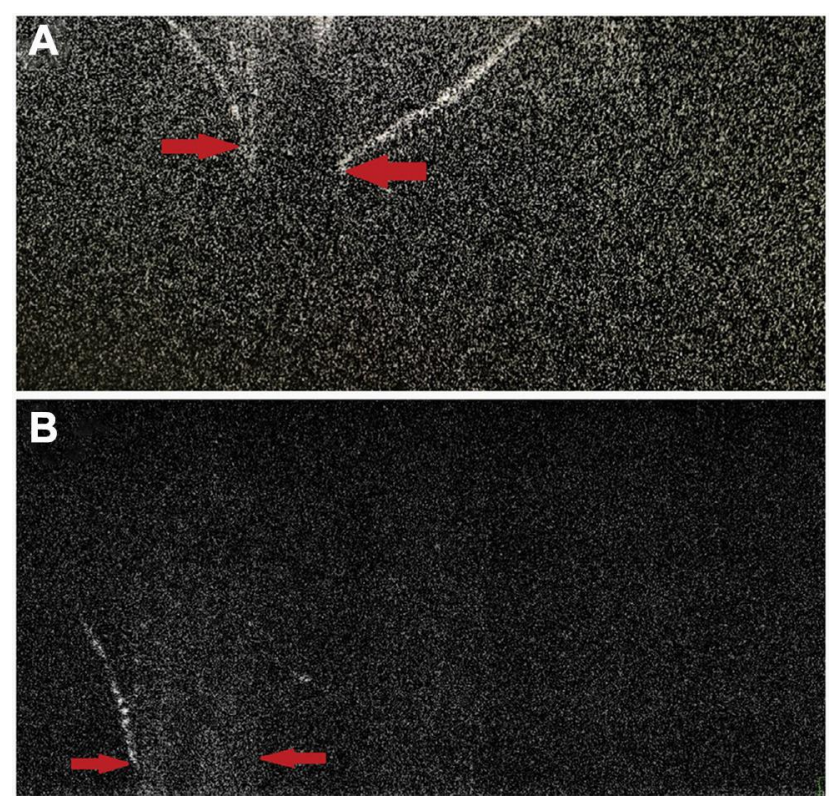

Figure 9 (A) In another two cases, posterior capsular dehiscence can be appreciated as posterior elongation of the torn capsule with active herniation of cortical matter (red arrows) (A, B)

Note: Reproduced from Pujari A, Sharma N. Post traumatic posterior capsular defect: assessment of 3 cases. J Cataract Refract Surg. 2019;45:1349-1350. ${ }^{37}$

3000, OCT RetinaScan Advance; Nidek, CA, USA) by converting it to an anterior segment OCT by placing a 20 D (Volk Optical, Mentor, OH) lens along its aperture (Figure 15). This adjustment will not scan the whole eye in one scan but by making such adjustments, anterior segment details can be scanned very easily until more sophisticated tools are available. ${ }^{36,37}$

\section{Limitations}

1) The stated preoperative and intraoperative findings in various forms of cataracts are still in the evolutionary phase; hence, conclusions from large samples are limited.

2) The majority of the observations were carried out by an isolated group of researchers; hence, geographic and socioeconomic variations are likely to limit the reproducibility and reliability of ASOCT findings under more complex case scenarios.

3) The use of more advanced swept source technology with an enhanced depth imaging modality is limited among the practitioners, this is because of the cost of the technology and limited expertise.

\section{Conclusions}

To conclude, ASOCT technology is comprehensively making progress in the assessment of cataractous eyes in the preoperative as well as intraoperative periods. The positive

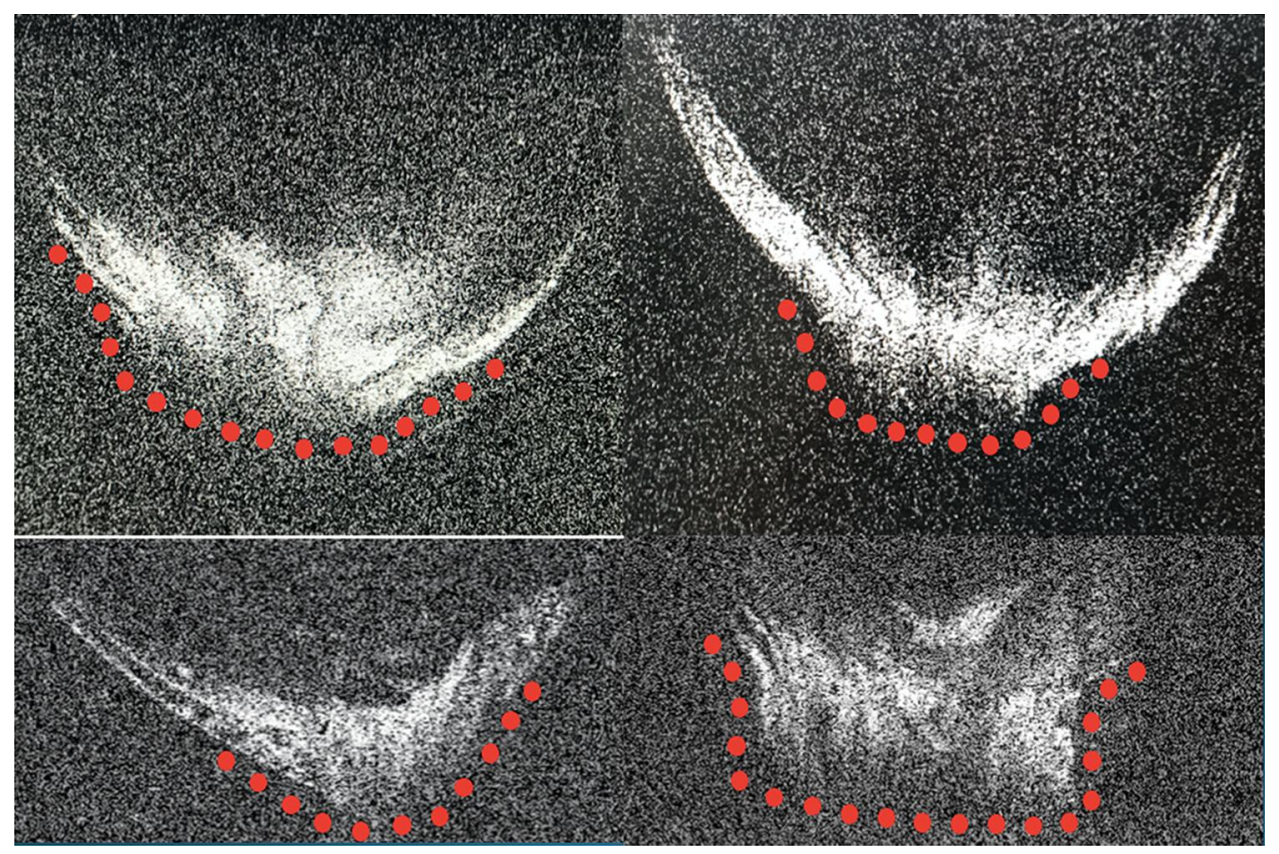

Figure 10 Four ASOCT images of posterior polar cataracts showing a definite dearth in posterior capsular continuity with active herniation of cortical matter into anterior vitreous (red dots). The consistent nipple-shaped configuration in these four images simulates a conical appearance (hence the conical sign) suggestive of posterior capsular deficiency.

Note: Reproduced from Pujari A, Selvan H, Yadav S, Urkude J, Singh R, Mukhija R, Makwana T, Sharma N. Preoperative assessment of posterior capsular integrity using a posterior segment OCT with a +20 D lens: The "conical sign" to suggest capsular deficiency in posterior polar cataracts. J Cataract Refract Surg. 2020;46(6):844-848. ${ }^{29}$ 


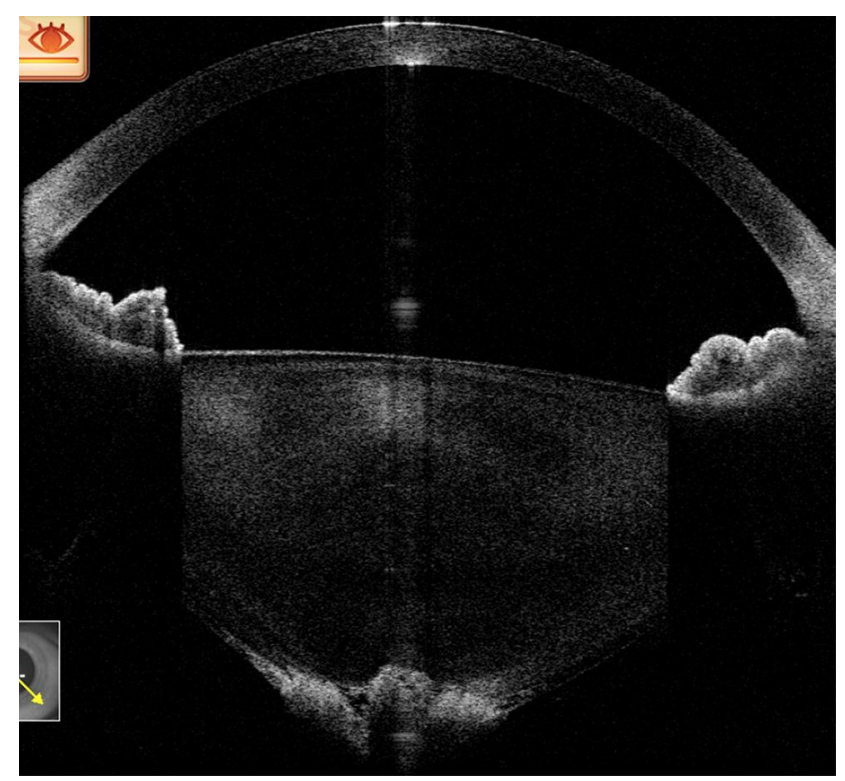

Figure II In a posterior polar cataract, posterior capsular deficiency with herniation of lens matter into anterior vitreous can be configured as the conical sign.

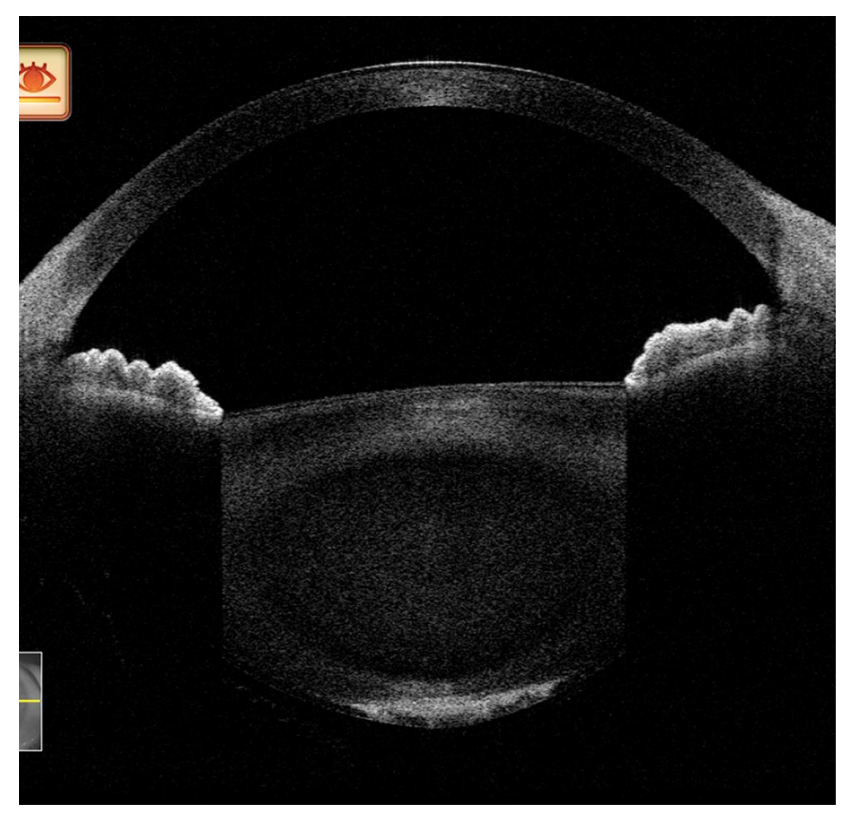

Figure I 3 In a posterior polar cataract, the presence of hypoechoic areas between the capsule and the opacity can be configured as a with-hypoechoic variant. (It should be noted that several other complicated variants of this type exist, and for better understanding a simpler variant has been shown here.)

role of ASOCT in objectifying the cataractous grade, intralenticular changes in white/mature cataracts, and posterior capsular changes in posterior polar and traumatic cataracts

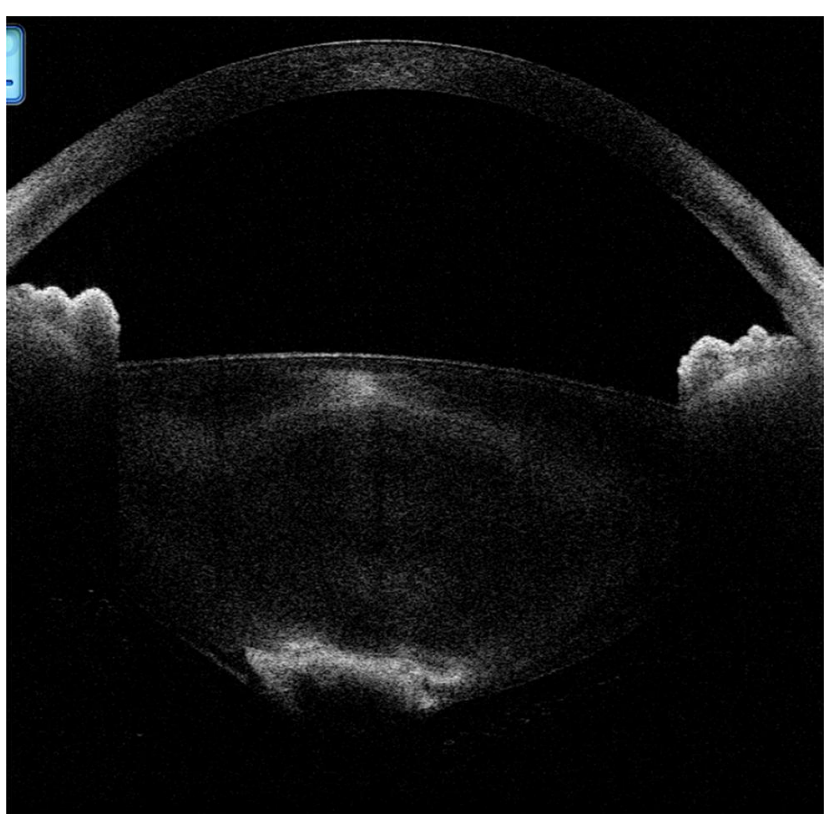

Figure $\mathbf{I} \mathbf{2}$ In another posterior polar cataract, the posterior lenticular appearance with deficient capsule can be configured as a moth-eaten appearance.

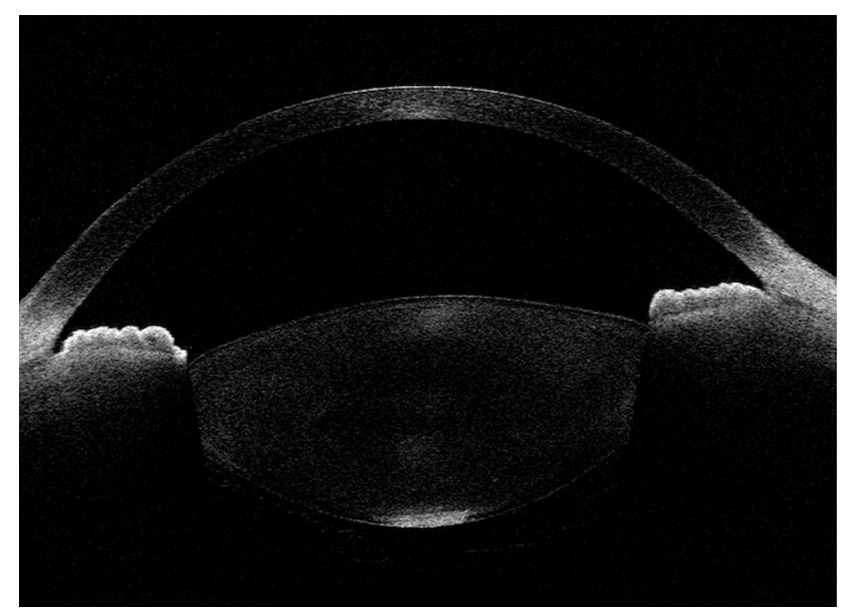

Figure I4 In a posterior polar cataract, the absence of hypoechoic areas between the opacity and the capsule can be configured as a without-hypoechoic variant. (It should be noted that several other complicated variants of this type exist, and for better understanding a simpler variant has been shown here.)

cases demonstrates its definite adjuvant role in routine clinical practice. In addition, compared to previous technologies, emerging swept source technology has furthered the cross-sectional imaging as a more practical tool. Hence, ASOCT is likely to become an integral part of assessment when dealing with complex lenticular entities in future. 


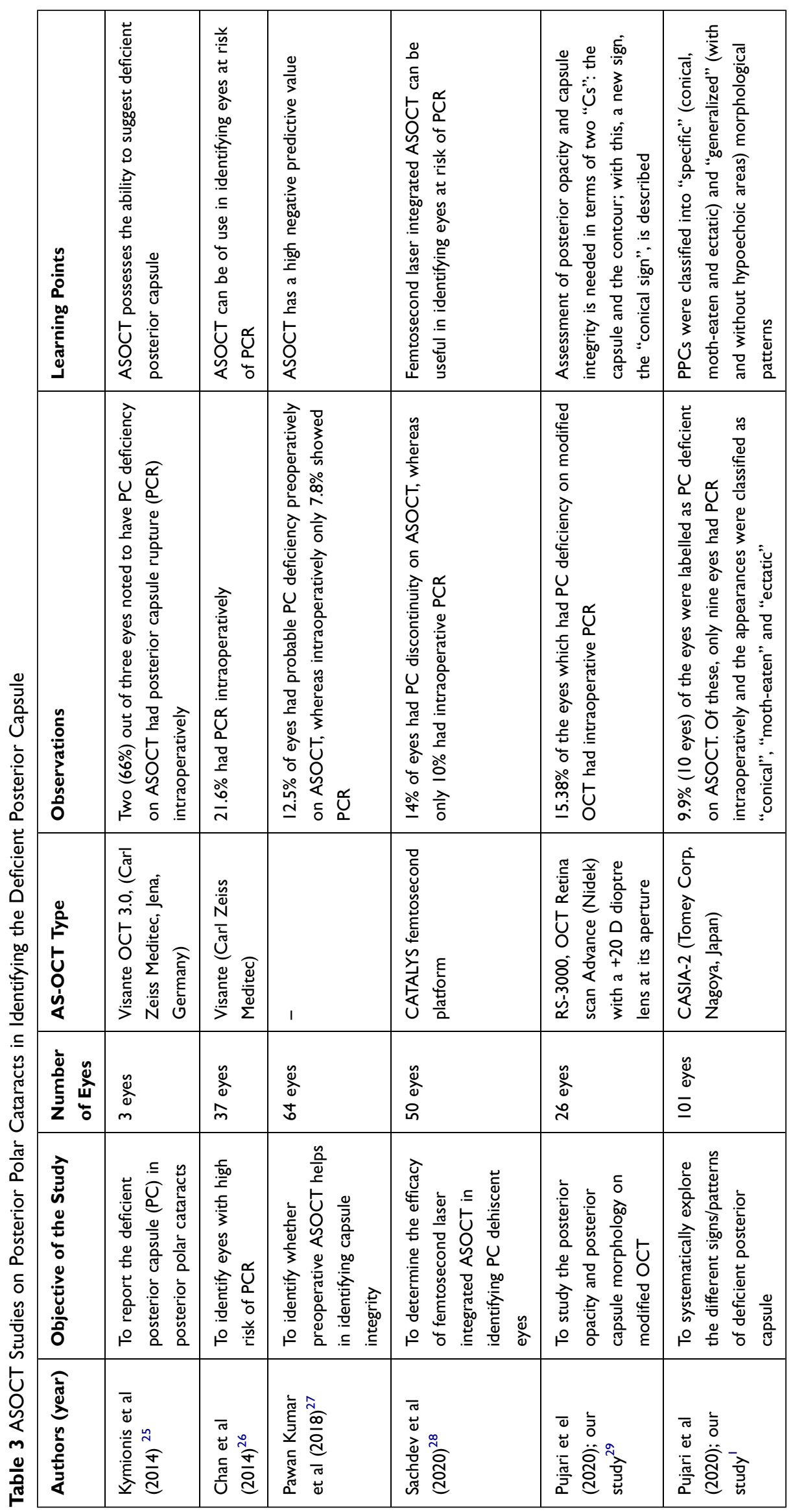




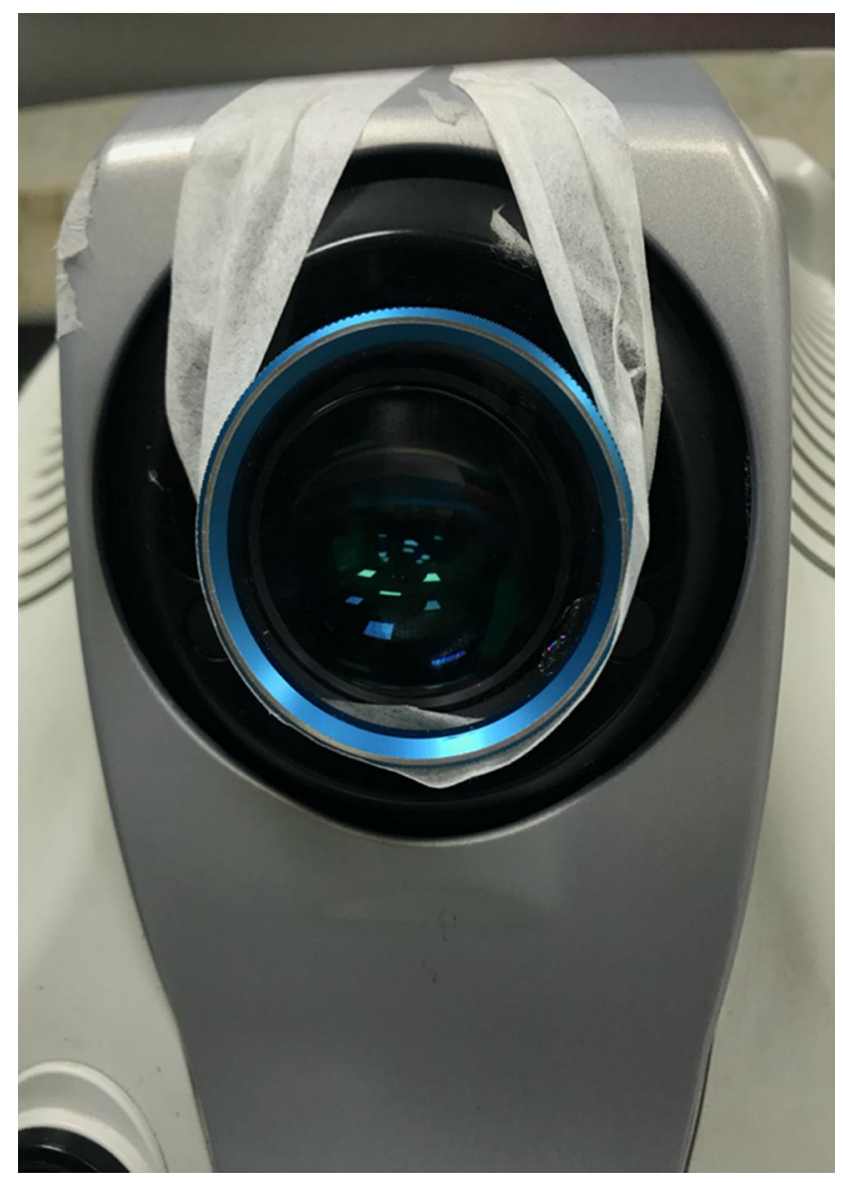

Figure $15 \mathrm{~A}+20$ lens mounted along the aperture of posterior segment OCT using a micropore tape. This will enable anterior segment imaging from the corneal surface to the posterior capsular tip (although not in one frame).

\section{Future Directions}

1) The advanced SS-ASOCT technology should be made available to all cataract surgeons who are dealing with complex cataractous cases.

2) Automated and artificial intelligence-driven objective nuclear sclerosis grading systems are likely to provide more uniform platforms with reduced subjective bias. In addition, such automations have the potential to suggest the need and benefits of cataract surgery in the near future.

3) The established key beneficial role of preoperative ASOCT in mature/white/hypermature, posterior polar, traumatic and other forms of complicated cataracts necessitates further critical research.

\section{Funding}

There is no funding to report.

\section{Disclosure}

The authors report no conflicts of interest in this work.

\section{References}

1. Pujari A, Yadav S, Sharma N, et al. Study 1: evaluation of the signs of deficient posterior capsule in posterior polar cataracts using anterior segment optical coherence tomography. J Cataract Refract Surg. 2020;46(9):1260-1265. doi:10.1097/j.jcrs.0000000000000246

2. Wong AL, Leung CK, Weinreb RN, et al. Quantitative assessment of lens opacities with anterior segment optical coherence tomography. Br J Ophthalmol. 2009;93(1):61-65. doi:10.1136/bjo.2008.137653

3. Brás JEG, Sickenberger W, Hirnschall N, Findl O. Cataract quantification using swept-source optical coherence tomography. J Cataract Refract Surg. 2018;44:1478-1481. doi:10.1016/j.jcrs.2018.08.009

4. Chen D, Li Z, Huang J, Yu L, Liu S, Zhao YE. Lens nuclear opacity quantitation with long-range swept-source optical coherence tomography: correlation to LOCS III and a Scheimpflug imaging-based grading system. $\mathrm{Br} \quad J$ Ophthalmol. 2019;103(8):1048-1053. doi:10.1136/bjophthalmol-2018-312661

5. Makhotkina NY, Berendschot TTJM, van den Biggelaar FJHM, Weik ARH, Nuijts RMMA. Comparability of subjective and objective measurements of nuclear density in cataract patients. Acta Ophthalmol. 2018;96(4):356-363. doi:10.1111/aos.13694

6. Panthier C, Burgos J, Rouger H, Saad A, Gatinel D. New objective lens density quantification method using swept-source optical coherence tomography technology: comparison with existing methods. J Cataract Refract Surg. 2017;43(12):1575-1581. doi:10.1016/j. jcrs.2017.09.028

7. Panthier C, de Wazieres A, Rouger H, Moran S, Saad A, Gatinel D. Average lens density quantification with swept-source optical coherence tomography: optimized, automated cataract grading technique. J Cataract Refract Surg. 2019;45(12):1746-1752. doi:10.1016/j. jcrs.2019.07.033

8. Nagy ZZ, Filkorn T, Takács AI, et al. Anterior segment OCT imaging after femtosecond laser cataract surgery. J Refract Surg. 2013;29 (2):110-112. doi:10.3928/1081597X-20130117-05

9. Palanker DV, Blumenkranz MS, Andersen D, et al. Femtosecond laser-assisted cataract surgery with integrated optical coherence tomography. Sci Transl Med. 2010;2(58):58ra85. doi:10.1126/ scitranslmed.3001305

10. Sun H, Fritz A, Dröge G, Neuhann T, Bille J.Femtosecond-LaserAssisted Cataract Surgery (FLACS) 2019 Aug 14. In: Bille JF, editor. High Resolution Imaging in Microscopy and Ophthalmology: New Frontiers in Biomedical Optics. Chapter 14. Cham (CH): Springer:2019. doi:10.1007/978-3-030-16638-0_14

11. Aly MG, Shams A, Fouad YA, Hamza I. Effect of lens thickness and nuclear density on the amount of laser fragmentation energy delivered during femtosecond laser-assisted cataract surgery. $J$ Cataract Refract Surg. 2019;45(4):485-489. doi:10.1016/j.jcrs.2018.11.014

12. Haeussler-Sinangin Y, Schultz T, Holtmann E, Dick HB. Primary posterior capsulotomy in femtosecond laser-assisted cataract surgery: in vivo spectral-domain optical coherence tomography study. J Cataract Refract Surg. 2016;42(9):1339-1344. doi:10.1016/j. jcrs.2016.06.037

13. Tassignon MJ, Ní Dhubhghaill S. Real-time intraoperative optical coherence tomography imaging confirms older concepts about the berger space. Ophthalmic Res. 2016;56(4):222-226. doi:10.1159/ 000446242

14. Das S, Kummelil MK, Kharbanda V, et al. Microscope integrated intraoperative spectral domain optical coherence tomography for cataract surgery: uses and applications. Curr Eye Res. 2016;41 (5):643-652. doi:10.3109/02713683.2015.1050742

15. Enaida H, Nakao I, Ishikawa S, Oshima Y, Ishibashi T. Optical coherence tomography imaging for gas-induced posterior subcapsular cataract after lens-sparing vitrectomy [published online ahead of print, 2020 Apr 16]. Can J Ophthalmol. 2020;S0008-4182 (20):30074. doi:10.1016/j.jcjo.2020.03.005 
16. Dhami A, Dhami AS, Singh H, Dhami GS. Role of anterior segment optical coherence tomography for safer management of mature white cataracts. J Cataract Refract Surg. 2019;45:480-484. doi:10.1016/j. jcrs.2018.11.009

17. Titiyal JS, Kaur M, Shaikh F, Goel S, Bageshwar LMS. Real-time intraoperative dynamics of white cataract-intraoperative optical coherence tomography-guided classification and management. $J$ Cataract Refract Surg. 2020;46(4):598-605. doi:10.1097/j. jcrs.0000000000000086

18. Pujari A, Selvan H, Urkude J, et al. Intralenticular changes in eyes with mature senile cataract on modified posterior segment optical coherence tomography. Indian J Ophthalmol. 2020;68:2099-2102. doi:10.4103/ijo.IJO_1650_19

19. Pujari A, Mukhija R, Azimeera S, Sharma N. Intralenticular changes on optical coherence tomography in eyes with mature brown cataract. $J$ Cataract Refract Surg. 2019;45(5):694-695. doi:10.1016/j. jcrs.2019.01.033

20. de Castro A, Benito A, Manzanera S, et al. Three-dimensional cataract crystalline lens imaging with swept-source optical coherence tomography. Invest Ophthalmol Vis Sci. 2018;59:897-903. doi:10.1167/iovs.17-23596

21. Kuriyan AE, Flynn HW Jr, Yoo SH. Subluxed traumatic cataract: optical coherence tomography findings and clinical management. Clin Ophthalmol. 2012;6:1997-1999. doi:10.2147/OPTH.S37393

22. Mahendradas P, Vijayan PB, Avadhani K, Garudadri S, Shetty BK. Usefulness of anterior segment optical coherence tomography in the demonstration of intralenticular foreign body in traumatic cataract. Can J Ophthalmol. 2010;45(4):413-414. doi:10.3129/i09-267

23. Prakash G, Ashokumar D, Jacob S, Kumar KS, Agarwal A, Agarwal AA. segment optical coherence tomography-aided diagnosis and primary posterior chamber intraocular lens implantation with fibrin glue in traumatic phacocele with scleral perforation. J Cataract Refract Surg. 2009;35 (4):782-784. doi:10.1016/j.jcrs.2008.09.031

24. Tabatabaei SA, Soleimani M, Etesali H, Naderan M. Accuracy of swept source optical coherence tomography and ultrasound biomicroscopy for evaluation of posterior lens capsule in traumatic cataract [published online ahead of print, 2020 Apr 2]. Am J Ophthalmol. 2020;S0002-9394(20):30141. doi:10.1016/j.ajo.2020.03.030

25. Kymionis GD, Diakonis VF, Liakopoulos DA, Tsoulnaras KI, Klados NE, Pallikaris IG. Anterior segment optical coherence tomography for demonstrating posterior capsular rent in posterior polar cataract. Clin Ophthalmol. 2014;8:215-217. doi:10.2147/OPTH.S55763

26. Chan TC, Li EY, Yau JC. Application of anterior segment optical coherence tomography to identify eyes with posterior polar cataract at high risk for posterior capsule rupture. J Cataract Refract Surg. 2014;40:2076-2081. doi:10.1016/j.jcrs.2014.03.033

27. Pavan Kumar G, Krishnamurthy P, Nath M, Baskaran P, Janani M, Venkatesh R. Can preoperative anterior segment optical coherence tomography predict posterior capsule rupture during phacoemulsification in patients with posterior polar cataract? J Cataract Refract Surg. 2018;44(12):1441-1445. doi:10.1016/j.jcrs.2018.07.056

Clinical Ophthalmology

\section{Publish your work in this journal}

Clinical Ophthalmology is an international, peer-reviewed journal covering all subspecialties within ophthalmology. Key topics include: Optometry; Visual science; Pharmacology and drug therapy in eye diseases; Basic Sciences; Primary and Secondary eye care; Patient Safety and Quality of Care Improvements. This journal is indexed on PubMed

Submit your manuscript here: https://www.dovepress.com/clinical-ophthalmology-journal
28. Sachdev MS, Malik R, Gupta H, Sachdev R, Sachdev GS Femtosecond laser-integrated anterior segment optical coherence tomography to detect preexisting posterior capsular dehiscence and increase safety in posterior polar cataracts. $J$ Cataract Refract Surg. 2020;46(2):235-240. doi:10.1097/j.jcrs.0000000000000048

29. Pujari A, Selvan H, Yadav S, et al. Preoperative assessment of posterior capsular integrity using a posterior segment OCT with a +20 D lens: the 'conical sign' to suggest capsular deficiency in posterior polar cataracts. J Cataract Refract Surg. 2020;46 (6):844-848. doi:10.1097/j.jcrs.0000000000000197

30. Choudhry N, Golding J, Rao RC. Cataractous mountain on the corneal horizon: swept-source optical coherence tomography. $J$ Cataract Refract Surg. 2016;42(7):1097. doi:10.1016/j.jcrs.2016.06.008

31. Amir-Asgari S, Hirnschall N, Findl O. Using continuous intraoperative optical coherence tomography to classify swirling lens fragments during cataract surgery and to predict their impact on corneal endothelial cell damage. $J$ Cataract Refract Surg. 2016;42:1029-1036. doi:10.1016/j.jcrs.2016.04.029

32. Chen CW, Francone AA, Gerber MJ, et al. Semiautomated optical coherence tomography-guided robotic surgery for porcine lens removal. J Cataract Refract Surg. 2019;45(11):1665-1669. doi:10.1016/j.jcrs.2019.06.020

33. Grulkowski I, Manzanera S, Cwiklinski L, et al. Volumetric macroand micro-scale assessment of crystalline lens opacities in cataract patients using long-depth-range swept source optical coherence tomography. Biomed Opt Express. 2018;9(8):3821-3833. doi:10.1364/BOE.9.003821

34. Kuo AN, McNabb RP, Izatt JA. Advances in Whole-Eye Optical Coherence Tomography Imaging [published online ahead of print, 2019 Mar 25]. Asia Pac J Ophthalmol (Phila). 2019. doi:10.22608/ APO.201901

35. Pujari A, Agarwal D, Chawla R, Kumar A, Sharma N. Intraoperative optical coherence tomography guided ocular surgeries: critical analysis of clinical role and future perspectives. Clin Ophthalmol. 2020;14:2427-2440. doi:10.2147/OPTH.S270708

36. Pujari A, Sharma N. Assessment of posterior capsular integrity on optical coherence tomography. Can $J$ Ophthalmol/Journal Canadien D'ophtalmologie. 2019;54(6):e302-e305. doi:10.1016/j.jcjo.2019.04.005

37. Pujari A, Sharma N. Post Traumatic posterior capsular defect: assessment of 3 cases. J Cataract Refract Surg. 2019;45:1349-1350. doi:10.1016/j.jcrs.2019.06.004
Central and CAS, and is the official journal of The Society of Clinical Ophthalmology (SCO). The manuscript management system is completely online and includes a very quick and fair peer-review system, which is all easy to use. Visit http://www.dovepress.com/ testimonials.php to read real quotes from published authors. 